\title{
The use of Vocalizations of the Sambirano Mouse Lemur (Microcebus sambiranensis) in an Acoustic Survey of Habitat Preference
}

\author{
Dan Hending ${ }^{1,2} \cdot$ Marc Holderied $^{1}$. \\ Grainne McCabe ${ }^{2}$
}

Received: 23 May 2017 / Accepted: 4 June 2017 / Published online: 19 July 2017

(C) The Author(s) 2017. This article is an open access publication

\begin{abstract}
Primate vocalizations convey a variety of information to conspecifics. The acoustic traits of these vocalizations are an effective vocal fingerprint to discriminate between sibling species for taxonomic diagnosis. However, the vocal behavior of nocturnal primates has been poorly studied and there are few studies of their vocal repertoires. We compiled a vocal repertoire for the Endangered Sambirano mouse lemur, Microcebus sambiranensis, an unstudied nocturnal primate of northwestern Madagascar, and compared the acoustic properties of one of their call types to those of $M$. murinus and $M$. rufus. We recorded vocalizations from radio-collared individuals using handheld recorders over 3 months. We also conducted an acoustic survey to measure the vocal activity of $M$. sambiranensis in four forest habitat types at the study site. We identified and classified five vocalization types in $M$. sambiranensis. The vocal repertoires of the three Microcebus species contain very similar call types but have different acoustic properties, with one loud call type, the whistle, having significantly different acoustic properties between species. Our acoustic survey detected more calls of M. sambiranensis in secondary forest, riparian forest, and forest edge habitats, suggesting that individuals may prefer these habitat types over primary forest. Our results suggest interspecific differences in the vocal repertoire of mouse lemurs, and that these differences can be used to investigate habitat preference via acoustic surveys.
\end{abstract}

Keywords Acoustic survey · Habitat - Microcebus Sambiranensis · Mouse lemurs · Vocalization - Vocal repertoire

Handling Editor: Joanna M. Setchell

Dan Hending

danhending2@gmail.com

1 School of Biological Sciences, The University of Bristol, Bristol BS8 1TH, UK

2 Bristol Zoological Society, Clifton, Bristol BS8 3HA, UK 


\section{Introduction}

Acoustic communication in animals carries a variety of information to conspecifics regarding predators, mating opportunities, and presence of food (Obrist 1995). Primate vocal communication is of particular interest because primates exhibit a variety of social systems and life histories that may influence vocal repertoire, and they communicate over both short and long distances (Marler and Mitani 1988). The comparative analysis of acoustic features of primate vocalizations can reveal phylogenetic relationships and is useful in the study of vocal evolution (Gamba et al. 2012). Examining the bioacoustic structure of primate communications can be a useful, inexpensive, and noninvasive method to diagnose sibling species (Braune et al. 2008; Zimmermann et al. 2000), particularly for cryptic species. Cryptic primates are often solitary so they must vocalize to find potential mates, and be able to discriminate between conspecifics, as well as between biologically and vocally similar members of sympatric cryptic species (Braune et al. 2008). Species-specific acoustic communication can help animals to communicate successfully with conspecifics and to avoid the risk of breeding with other species.

An understanding of species-specific vocal repertoires can also be used to develop remote population monitoring tools for species-specific conservation (Gamba and Giacoma 2007). If a species can be identified through its vocal acoustic properties, bioacoustic surveys can be used to investigate species-specific vocal activity (Terry et al. 2005). Bioacoustic surveys are a noninvasive method of obtaining vocalization activity data and have been used successfully in studies of birds (Baldo and Mennill 2011; Dawson and Efford 2009), bats (Hackett et al. 2011; Obrist 1995), frogs (Love and Bee 2010; Penny et al. 2014), and marine habitats (Jolly and Hampton 2011). Such surveys are ideal for investigating animal habitat preference, population distributions within tropical forests, and the influence of habitat on animal vocal repertoires (Drew 2014). Different habitats have different sound transmission properties owing to their varying vegetation structures and microclimates (Wiley and Richards 1982). Changes in habitat structure alter sound transmission properties, which can lead to changes in the acoustic properties of vocalizations over very short or evolutionary periods of time (Slabbekoorn and Smith 2002). Acoustic surveys of primate calls have been used in studies of galagos (Masters 1991), tarsiers (Nietsch and Kopp 1998), and diurnal South American primates (Whitehead 1995). Although they have potential to analyze primate habitat preference, they have not yet been used to do so. Acoustic surveys have the potential to aid in the conservation of primate habitats, all of which are severely threatened by deforestation and habitat degradation (Ganzhorn 1987; Jolly and Sussman 2006; Schwitzer et al. 2011).

Many new species of cryptic, nocturnal primates, including lemurs (Mittermeier et al. 2010), lorises (Munds et al. 2013), and galagos (Masters and Couette 2015), have been described in the past 10 years and their sociobiology is poorly studied (RodeMargono et al. 2016). Several of these species are almost morphologically identical, posing a problem for species-specific studies and conservation management (Henry 1985). For example, the mouse lemur genus, Microcebus, contains 24 species of nocturnal cryptic primates that are widely distributed throughout the forest habitats of Madagascar, often with high population densities (Kappeler and Rasoloarison 2003; Radespiel 2006). All 24 species diverged from one another recently as a result of 
genetic divergence in isolated subpopulations (Hotaling et al. 2016; Mittermeier et al. 2008). This accelerated speciation was caused by habitat fragmentation and natural barriers such as river catchments and extreme topography that the small-bodied lemurs are unable to cross (Wilme et al. 2006). Vocal fingerprinting is an effective means to discriminate between mouse lemurs (Zimmermann et al. 2000). For example, the acoustic properties of calls of M. murinus and M. rufus differ significantly, and this difference may be influenced by habitat (Zimmermann et al. 2000). No acoustic surveys have been conducted to investigate the specific habitat preference or population distribution of mouse lemurs.

We compiled a vocal repertoire for the Endangered Microcebus sambiranensis, or Sambirano mouse lemur, one of the smallest Microcebus species, which inhabits two isolated forests in northwestern Madagascar (Randriatahina et al. 2014; Rasoloarison et al. 2000). We compared this species' vocal acoustic properties to the calls of two closely related species: $M$. murinus and M. rufus. We hypothesized that vocalizations of the three species will differ in their acoustic properties, owing to their different habitats. In parallel, we used an acoustic survey of $M$. sambiranensis vocal activity to investigate the species' use and preference of different forest habitats at the study site. We hypothesized that the frequency of acoustic call detection would vary between the selected habitat types. We predicted that we would detect a higher frequency of acoustic calls in habitats composed of predominantly secondary growth with denser vegetation because these habitat types would provide the vulnerable, small-bodied mouse lemurs with better protection and concealment from predators such as owls and snakes (Perret 1998), and are therefore likely to have a higher population density of M. sambiranensis.

\section{Methods}

\section{Study Site}

The Anabohazo Forest is in the northeast sector $\left(\mathrm{S} 14^{\circ} 19^{\prime}, \mathrm{E} 47^{\circ} 54^{\prime}\right)$ of Sahamalaza-Iles Radama National Park (Fig. 1) in the Sofia region of northwestern Madagascar (Seiler et al. 2013). Sahamalaza has been a UNESCO Biosphere Reserve since 2001 and was given National Park status in 2007 (Volampeno et al. 2015). Managed by Madagascar National Parks (MNP), the protected area of the Sahamalaza-Iles Radama National

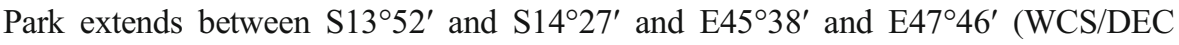
2002). Sahamalaza-Iles Radama National Park lies within the Sambirano domain of Madagascar, a transitional area between the rainforests of the north and the dry, deciduous forests of the west (Project ZICOMA 1999), where the climate is hot and subhumid (Andreone et al. 2001). There is a hotter, wet season from November until April with a mean temperature of $32.0^{\circ} \mathrm{C}$ followed by a cooler, dry season from May until October with a mean temperature of $20.6{ }^{\circ} \mathrm{C}$ (Schwitzer et al. 2007a, b). The mean precipitation for the area is $1750 \mathrm{~mm}$ of rainfall (Project ZICOMA 1999), most of which falls in the wet season. Anabohazo is a semihumid forest, characterized by rolling hills of ca. 300-350 m a.s.l. that are intersected by small, seasonal streams (Andreone et al. 2001). The total area of the Anabohazo forest is 5275 ha, the largest of the three forest blocks remaining on the peninsula, the others being Ankarafa and Analavory (Randriatahina et al. 2014). The vegetation is characteristic of the western 


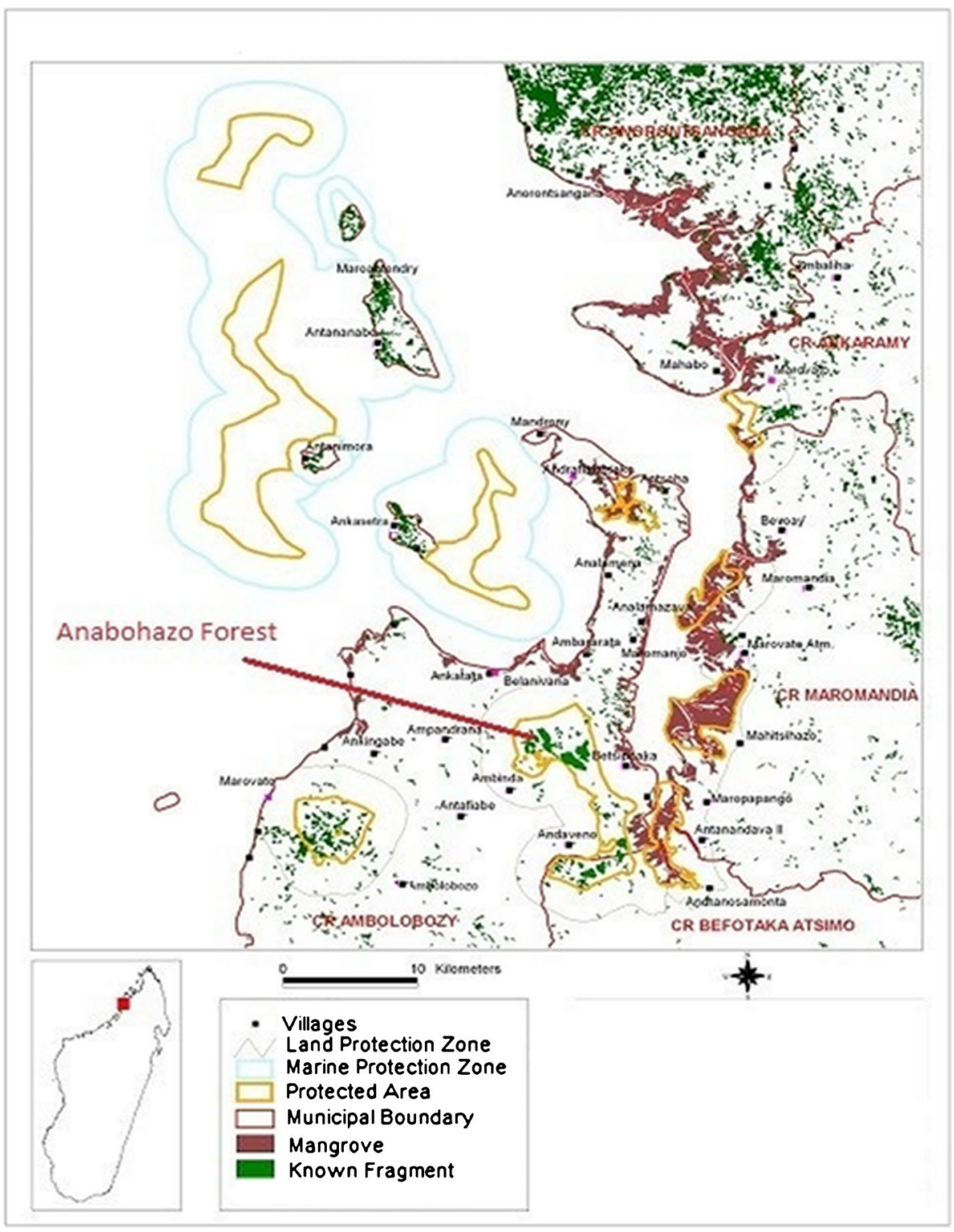

Fig. 1 Location of Anabohazo in Sahamalaza-Iles Radama National Park, northwestern Madagascar. (Adapted from Wildlife Conservation Society Madagascar 2006).

dry forests of Madagascar but there are many tree species here that are unique to the Sambirano domain (Birkinshaw 2004).

Sahamalaza-Iles Radama National Park harbors eight different lemur species, including the last remaining populations of the Critically Endangered blue-eyed black lemur, Eulemur flavifrons and the Sahamalaza sportive lemur, Lepilemur sahamalazensis (Schwitzer et al. 2013). Other lemur species found here are the Endangered northern giant mouse lemur, Mirza zaza, and aye-aye, Daubentonia 
madagascariensis; the Vulnerable black lemur, Eulemur macaco and western bamboo lemur, Hapalemur occidentalis; and the fat-tailed dwarf lemur, Cheirogaleus medius. The presence of Microcebus sambiranensis was first confirmed in the National Park in 2014 (Randriatahina et al. 2014). Lemur populations here are threatened by habitat destruction due to slash-and-burn agriculture, in addition to selective logging and mining (Seiler et al. 2010).

\section{Reference Vocal Collection}

We captured five male and three female Microcebus sambiranensis individuals by hand and using 10 live-traps (LFG Folding Trap, Sherman, Tallahassee, FL, USA) over 4 days at the start of the study, March 23, 2015- March 26, 2015. We set the traps nightly at 18:00 $\mathrm{h}$ and checked them every hour until 02:00 $\mathrm{h}$. We logged GPS waypoints of the capture site trees. We anesthetized captured individuals with $10 \mathrm{mg} /$ $\mathrm{kg}$ of Telazol® anesthetic; identified their sex; and recorded their head length, body length, tail length, and total body mass using Vernier callipers and spring scales. We collared the captured individuals with TW4 PiP light-weight collars (BioTrack, Wareham, UK; frequency range 150.061-150.508). A trained, experienced veterinarian secured collars around the subject's neck using a zip tie and tightened it so that accidental asphyxiation did not occur. We cut off any remaining exposed length of cable tie using scissors. Once the collared M. sambiranensis individuals had fully recovered from the effects of the anesthetic, a recovery time of ca. $8 \mathrm{~h}$, we released them at the tree in which they were captured.

We tracked radio-collared individuals using a portable radio receiver (Regal 2000, Titley Scientific, Columbia, MO, USA) with a two-element antenna (Titley Scientific, Columbia, MO, USA) during night observations (18:00-04:00 h) from March 27, 2015 to May 31, 2015. We collected $350 \mathrm{~h}$ of night observations, tracking one lemur per night. We recorded any vocal activity of the collared lemurs using a portable handheld recorder (R-05, Roland, Hamamatsu, Japan) equipped with an internal stereo microphone set to a sampling rate of $96 \mathrm{kHz}$, and saved recordings as $320 \mathrm{kbps}$ WAV audio files. We set the sampling rate to $96 \mathrm{kHz}$ because some known vocalizations of mouse lemurs go into the ultrasound frequency range (Braune et al. 2005). The handheld recorder had a $128 \times 64$ dot graphic display screen that indicated any nearby sound up to $48 \mathrm{kHz}$ detected by the internal microphone, even if the microphone was not recording. This allowed us to identify when our collared individuals were vocalizing in the ultrasound range, enabling us to record the higher frequency vocalizations although we could not hear them ourselves. We used focal observations of the vocalizing individuals to determine the context in which the vocalization was being used. We noted any interactions with other mouse lemurs, responses to stimuli such as predator presence and specific behaviors if they corresponded to or triggered a vocalization, a method previously used to determine call context in other mouse lemurs (Braune et al. 2005; Scheumann et al. 2007).

\section{Reference Vocal Extraction}

To compile the vocal repertoire, we selected only the highest quality vocalizations with a low level of background recording noise from the $96-\mathrm{kHz}$ sampling rate handheld 
recorder data. We used SASLab Pro 5.2.07 (Avisoft Bioacoustics, Berlin, Germany) to filter out frequencies of background noise; weather disturbance such as wind and rain; and the loud calls of other animals such as bats, frogs, insects, and zebu cattle. We used a finite impulse response (FIR) filter, a method successfully used by Love and Bee (2010). We used a high-pass FIR filter for vocalizations at a frequency of $15 \mathrm{kHz}$ or more, with a cutoff of $14 \mathrm{kHz}$. For lower frequency vocalizations, we used a low-pass FIR filter with a cutoff frequency of $15 \mathrm{kHz}$. For any vocalizations with a fundamental frequency of around 14-15 kHz, we used a low-pass FIR filter with a cutoff frequency of $20 \mathrm{kHz}$. We also analyzed all recorded vocalizations by ear at a lower playback frequency, $22.1 \mathrm{kHz}$, to bring them fully into the human auditory frequency range. We normalized the vocalization amplitude to $90 \%$ of the recording range, and deleted any remaining unwanted background noise manually using the spectrogram eraser function. We then analyzed the acoustic properties of individual vocalization units to preclassify our recorded vocal types. We preclassified vocalization types according to a pilot acoustic study of gray mouse lemurs, Microcebus murinus, at Bristol Zoo Gardens (D. Hending, unpubl. Data) and to similar vocalizations published for other mouse lemur species (Braune et al. 2005; Cherry et al. 1987; Glatston 1979; Leliveld et al. 2011; Zimmermann et al. 2000). We defined vocalizations as a single unit if call units were separated from each other by a silence more than double the call unit's duration, and multiunit if the call interval was less than double the unit's duration (Rasoloharijaona et al. 2006). We used the automatic parameters measurement function in SASLab Pro to create a table of temporal and frequency parameters from a DDE parameter file for frequently recorded vocalizations (Table I).

Table I Descriptions of acoustic parameters measured from spectrograms of Microcebus sambiranensis vocalizations recorded in Anabohazo forest, northwest Madagascar (March 27, 2015-May 31, 2015), using the automatic parameters measurement function in SASLab Pro

\begin{tabular}{|c|c|}
\hline Acoustic Parameter & Description \\
\hline Duration (s) & Time between the onset and offset of a call unit \\
\hline Interval (s) & Time between the offset of one unit and the onset of the next unit \\
\hline Disttomax (s) & $\begin{array}{l}\text { Time between the onset of the unit and the unit's point of maximum } \\
\text { frequency }\end{array}$ \\
\hline Mean peak frequency $(\mathrm{Hz})$ & Mean frequency at maximum amplitude during the unit's total duration \\
\hline Mean minimum frequency $(\mathrm{Hz})$ & Mean minimum frequency during the unit's total duration \\
\hline Mean maximum frequency $(\mathrm{Hz})$ & Mean maximum frequency during the unit's total duration \\
\hline Mean bandwidth $(\mathrm{Hz})$ & $\begin{array}{l}\text { Range between the mean minimum and mean maximum frequencies } \\
\text { for the total unit duration }\end{array}$ \\
\hline Start peak frequency $(\mathrm{Hz})$ & Frequency at maximum amplitude of the unit start \\
\hline Start minimum frequency $(\mathrm{Hz})$ & Minimum frequency at the onset of the unit \\
\hline Start maximum frequency $(\mathrm{Hz})$ & Maximum frequency at the onset of the unit \\
\hline Start bandwidth $(\mathrm{Hz})$ & Range between maximum and minimum start frequency \\
\hline End peak frequency $(\mathrm{Hz})$ & Frequency at maximum amplitude of the unit end \\
\hline End minimum frequency $(\mathrm{Hz})$ & Minimum frequency at the offset of the unit \\
\hline End maximum frequency $(\mathrm{Hz})$ & Maximum frequency at the offset of the unit \\
\hline End bandwidth $(\mathrm{Hz})$ & Range between maximum and minimum end frequency \\
\hline
\end{tabular}




\section{Species Comparison}

We compared six acoustic parameters of one call type, the whistle, between three mouse lemur species using the acoustics parameters of Whistle Type 1 for Microcebus sambiranensis from this study and data harvested from the published results of Zimmermann et al. (2000) for M. murinus and M. rufus. We used the means, standard deviations, and sample sizes for each variable as we had no raw data for M. murinus and M. rufus.

\section{Selection of Acoustic Survey Habitats}

We selected four habitat types for acoustic surveys: (1) primary forest, (2) secondary forest, (3) riparian forest, and (4) forest edge, including the boundary of large vegetation clearings (Fig. 2). We characterized each habitat using preliminary vegetation plot data (F. Ramiadantsihoarana unpubl. Data). We characterized primary forest as areas of undisturbed forest dominated by sparsely distributed, old-growth trees with a mean diameter at breast height (DBH) of $\geq 200 \mathrm{~mm}$; secondary forest as areas of densely vegetated juvenile or subadult trees with a mean DBH of $<200 \mathrm{~mm}$; riparian forest as an area of forest within and not more than $10 \mathrm{~m}$ away from a flowing water source or dry stream bed; and forest edge/boundary as an area of forest within and not more than $10 \mathrm{~m}$ away from a large open area.

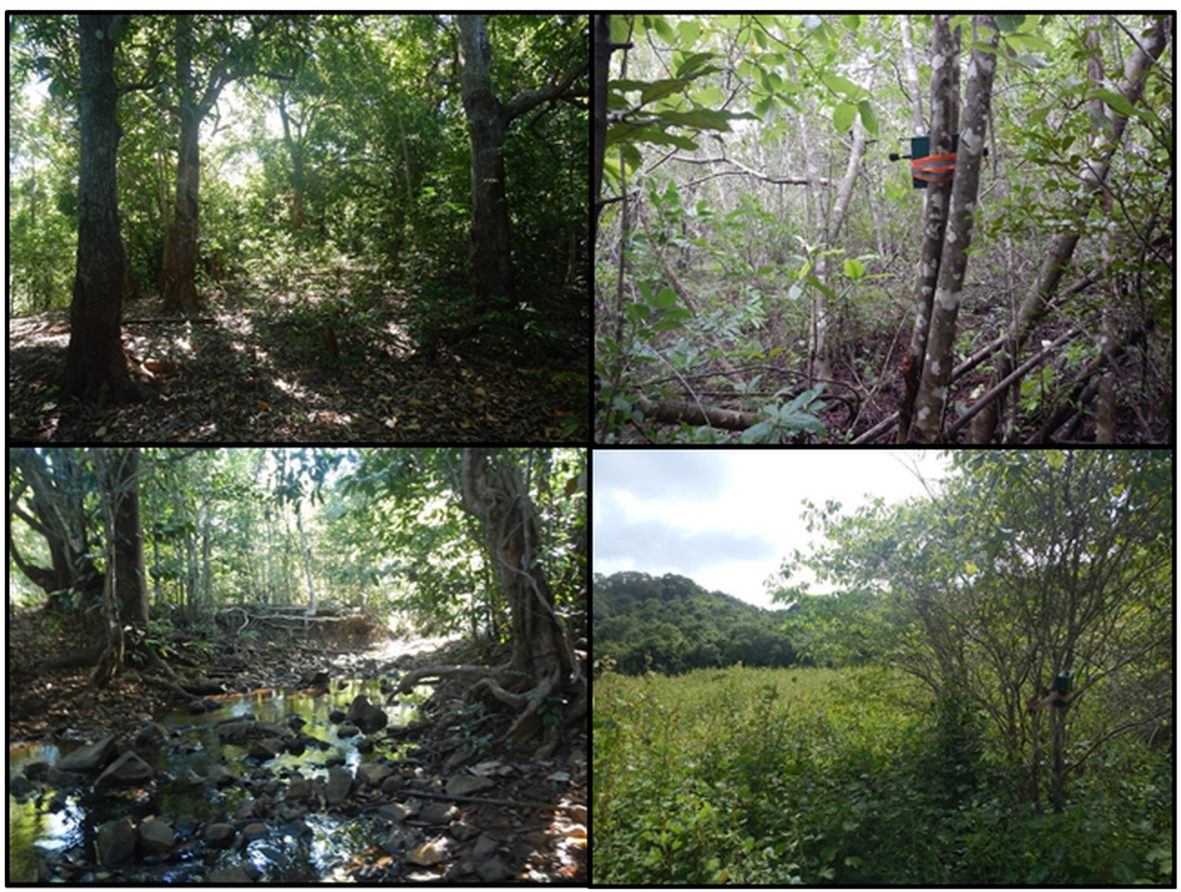

Fig. 2 Habitat types selected for acoustic surveying of Microcebus sambiranensis, March 1, 2015-May 31, 2015 in Anabohazo forest, northwest Madagascar. Clockwise from top left: Primary forest, secondary forest, forest edge, and riparian forest. The acoustic recorder can be seen in secondary forest and forest edge. 
We then selected five different sites for each habitat type, resulting in a total of 20 sites for acoustic recording. We selected the order of acoustic monitoring at each site at random and positioned the recording equipment $\geq 50 \mathrm{~m}$ away from human-made paths used by local villagers to access neighboring villages. This was to minimize humanproduced noise recorded and human interference. The 20 chosen sites were spread through 80 ha of the study site: $1.5 \%$ of the total area of Anabohazo forest, and over an altitude of $245-359 \mathrm{~m}$.

\section{Acoustic Habitat Surveys}

We conducted acoustic surveys from March 1, 2015 until May 31, 2015, the transitional phase between the wet and dry season, using an automated terrestrial wildlife acoustic recorder (Song Meter SM2+, Wildlife Acoustics, Maynard, MA, USA) equipped with two weather-proof microphones (SMX-II, Wildlife Acoustics, Maynard, MA, USA). We attached the acoustic recorder to a tree at the recording site at a height of 1.0-1.5 m above the ground so that the chance of device tampering by rats and other small grounddwelling animals was minimal, an approach used by Hackett et al. (2011). The acoustic recorder produced stereo files at a 48-kHz sampling rate, 16-bit resolution, resulting in $320 \mathrm{kbps}$ WAV audio files, an approach that has worked successfully in other acoustic surveys of terrestrial organisms (Baldo and Mennill 2011). We chose a 48-kHz sampling rate because we expected it to be sufficiently high to record the fundamental harmonic of all $M$. sambiranensis vocalizations in the vicinity of our acoustic recorder. We tested and confirmed this in a pilot acoustic study of captive Microcebus murinus vocalizations at Bristol Zoo Gardens (D. Hending unpubl. Data). We recorded from 18:00 h to 06:00 h for three repeat nights at each site, a total of 60 nights worth of recording. We saved recordings as four 3-h WAV files per night.

\section{Acoustic Survey Vocal Extraction}

We converted stereo WAV files from the acoustic survey into mono WAV files by removing the channel of the recording with the lowest recorded volume in SASLab Pro 5.2.07 (Avisoft Bioacoustics, Berlin, Germany). We split them into 10-s recordings with an accompanying spectrogram for visual analysis in MATLAB ${ }^{\circledR}$ R2014a (MathWorks, Natick, MA, USA) using the splitWAVs_batch script. In total, the 12-h recordings from the 60 nights of the acoustic survey required 263,700 ten-second audio files with spectrograms. The MATLAB® spectrograms displayed lemur vocalizations clearly and enabled us to visually check for the presence of Microcebus sambiranensis vocal activity. We could examine two or three spectrograms in $1 \mathrm{~s}$ to detect mouse lemur vocalizations. Due to our sampling rate of $48 \mathrm{kHz}$, it was possible that some of the higher frequency calls may have been only partially recorded. We only included calls that were fully, not partially, visible in our MATLAB $®$ spectrograms for analysis of the acoustic survey results, and were therefore unable to compare the number of partially recorded calls between habitat types. Additionally, we were very conservative in our selection of calls for analysis from the acoustic survey; we only included calls with a peak amplitude at least $19 \mathrm{~dB}$ above the background noise level. We did not measure or analyze the acoustic properties of calls recorded in the acoustic survey and we did not include them in our vocal repertoire compilation. 


\section{Data Analysis}

We conducted statistics on recorded vocalization types in IBM SPSS 21.0 (SPSS Inc., Chicago, IL, USA). For acoustic classification of call types, we $\log$ transformed $\left(\log _{\mathrm{e}}\right)$ the highly skewed acoustic parameter data for ease of interpretation and to meet the normality assumptions of further analyses. We used principal component analysis (PCA) to condense the large set of measured variables into a smaller set of principal components. We then used stepwise discriminant function analysis (DFA) with leaveone-out cross validation of these principal components to test whether our identified, preclassified vocalization types were qualitatively classified as distinct vocal groups. We used one-way ANOVA to test for significant differences in the acoustic parameters of whistle calls between Microcebus sambiranensis, M. murinus, and M. rufus. For these multiple comparisons, we applied Bonferroni correction $(a=0.05 / N$, where $N$ is the number of comparisons). We used a univariate general linear model to suggest habitat preference by analyzing which habitat types had a significantly larger number of mouse lemur vocalizations. The dataset met the assumptions of the linear model, where the response variable was habitat type. We counted multiunit calls as one vocalization. We used an $\alpha$ level of 0.05 for all analyses except where we applied the Bonferroni correction.

\section{Ethical Note}

All research complied with UK Home Office policies when working with animals and all research adhered to the legal requirements of Madagascar. Research in the SahamalazaIles Radama National Park was permitted by Madagascar National Parks (Permit number 049/15/MEEF/SG/DGF/DCB.SAP/SCB). We consulted the Code of Best Practices for Field Primatology when planning all methods undertaken in this study. Capturing and collaring of the study population individuals took place under the supervision of a professional, experienced veterinarian team; details of the procedure are described in the Reference Vocal Collection section. At the end of the study, the veterinarian team recaptured all radio collared individuals and removed the radio collars using a pair of scissors. We released the individuals at the tree in which we captured them.

\section{Data Availability}

The datasets generated and analyzed during the current study are available from the corresponding author on reasonable request.

\section{Results}

\section{Vocal Repertoire and Behavioral Context}

We recorded 71 mouse lemur vocalizations during $350 \mathrm{~h}$ of opportunistic handheld recording, a rate of 0.2 vocalizations per hour. After analyzing these recordings, we 
preclassified five vocal types for Microcebus sambiranensis based on spectral (Fig. 3) and acoustic properties (Table II). Some call types were single unit and others were multiunit.

PCA identified four call parameters as principal components for call type discrimination, which we submitted to the DFA (Table III). DFA revealed significant differences between our five preclassified vocal types (Wilk's $\lambda=0.013, F_{56,1592}=7.076, P$ $<0.001$ ). Leave-one-out cross-validation correctly classified $96.4 \%$ of the preclassified vocalizations by call type (Table IV). All Whistle Type 1, Whistle Type 3, Chitter and Purr calls were classified correctly. Whistle Type 2 had a lower classification rate of $89.5 \%$, with $10.5 \%$ of cases being classified as Whistle Type 1 .

Our correctly classified vocal types are distinct when plotted on a scatterplot of the first two principal components (Fig. 4a). When inspected more closely, the three whistle calls spread out slightly despite their similar acoustic properties and spectrographic appearances (Fig. 4b).

We observed Whistle Type 1 the most frequently of the five vocalizations. It is a tonal, single-unit loud call where the frequency rises at a shallow gradient throughout the duration of the call. The call is a single piercing unit and is always used in a repeated sequence. The frequency of the call increases by $2.7 \mathrm{kHz}$ between the onset and offset (Table II). We always observed the call being emitted by a lone adult attempting to communicate with other members of the population, with no obvious threat, over a long distance.

We observed Whistle Type 2 on three occasions, where it was repeated for at least half an hour. Like Whistle Type 1, it is a tonal, piercing single unit loud call with a rising frequency throughout the call unit. Figure $3 \mathrm{~b}$ shows that this call is very similar to Whistle Type 1 (Fig. 3a) but has a harmonic overtone at a frequency of $30-44 \mathrm{kHz}$ and a steeper rise in frequency throughout the call unit. Its acoustic properties are
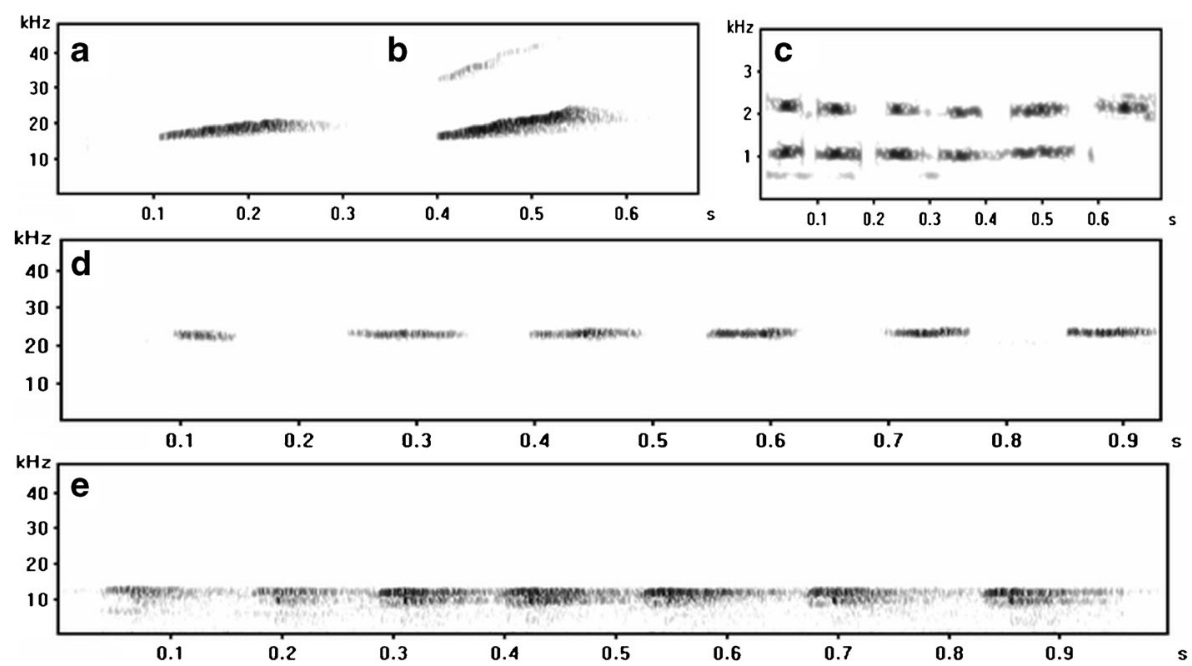

Fig. 3 Spectrograms of the five recorded calls of Microcebus sambiranensis created from separate sound files, recorded in Anabohazo forest, northwestern Madagascar (March 27, 2015-May 31, 2015). a Whistle Type 1. b Whistle Type 2. c Purr. d Whistle Type 3. e Chitter. Generated in Avisoft SASLab Pro; FFT length: 512 points; 1024-point Hamming Window; $96 \mathrm{kHz}$ sampling rate; $50 \%$ window overlap resulting in $188 \mathrm{~Hz}$ frequency resolution and $2.67 \mathrm{~ms}$ temporal resolution. 


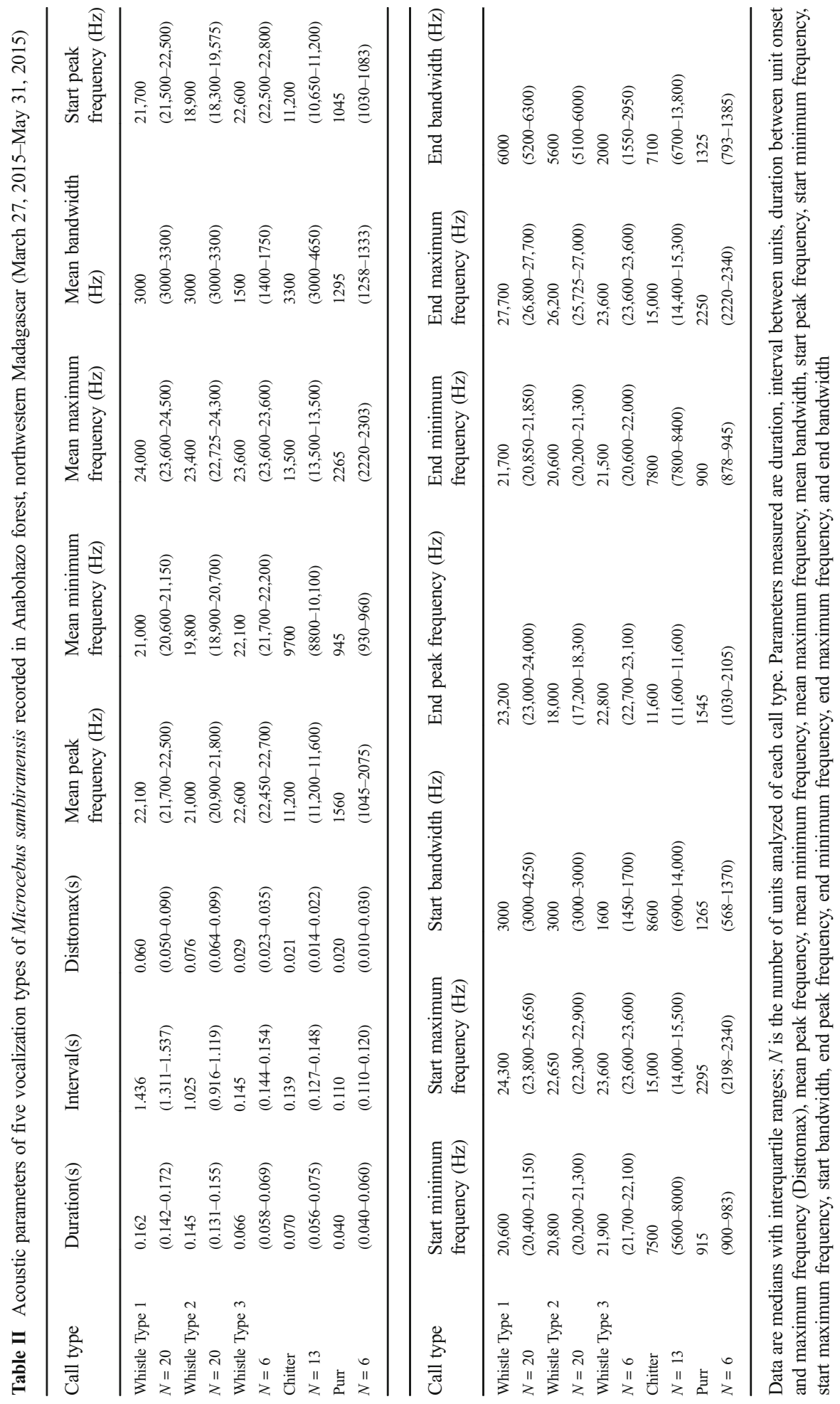


Table III Principal component call parameters contributing to the discrimination and classification of Microcebus sambiranensis call types recorded in Anabohazo forest, north-western Madagascar (March 27, 2015-May 31, 2015)

\begin{tabular}{lllll}
\hline Principal call components & $\begin{array}{l}\text { Mean } \\
\text { minimum } \\
\text { frequency }\end{array}$ & $\begin{array}{l}\text { Mean minimum } \\
\text { frequency, mean } \\
\text { maximum } \\
\text { frequency }\end{array}$ & $\begin{array}{l}\text { Mean minimum } \\
\text { frequency; mean } \\
\text { maximum frequency, } \\
\text { mean bandwidth }\end{array}$ & $\begin{array}{l}\text { Mean minimum frequency; } \\
\text { mean maximum frequency; } \\
\text { frequency }\end{array}$ \\
\hline Discriminant function & 1 & 2 & 3 & 4 \\
Variance $(\%)$ & 93.0 & 4.9 & 1.7 & 0.4 \\
Eigenvalue & 525.420 & 27.829 & 9.703 & 2.245 \\
Canonical correlation & 0.999 & 0.983 & 0.952 & 0.832 \\
Wilks' $\lambda$ & 0.000 & 0.001 & 0.029 & 0.308 \\
df & 60 & 42 & 26 & 12 \\
Sig. & $<0.001$ & $<0.001$ & $<0.001$ & $<0.001$ \\
\hline
\end{tabular}

similar to those of Whistle Type 1 (Table II). However, we observed this call being used by adults only when a potential threat was nearby such as a snake in the caller's tree or an owl in the immediate vicinity. Therefore, it may function as an alarm call or a distress signal. We recorded all Whistle Type 2 calls during the final 3 weeks of the field season; the collared individuals were well habituated by this time and it is unlikely that any distress call was due to the presence of a researcher.

The Purr is a soft multiunit call with a frequency of around $1 \mathrm{kHz}$. It has a second harmonic overtone that is double the frequency (Table II, Fig. 3c). We observed it on one occasion between two adults with overlapping home ranges during allo-grooming. It is similar spectrographically to the Microcebus murinus Purr detailed in Glatston (1979).

We heard Whistle Type 3 once, from a lone adult. Unlike the other two whistle type calls described here it is multiunit. The Chitter call is also a multiunit, tonal call that was used between two members of the population over a short distance.

Table IV Percentages and call type numbers of call classification results from stepwise discriminant function analysis with leave-one-out cross validation analysis for calls of Microcebus sambiranensis recorded in Anabohazo forest, northwestern Madagascar (March 27, 2015-May 31, 2015)

\begin{tabular}{|c|c|c|c|c|c|}
\hline \multirow[t]{2}{*}{ Call type } & \multicolumn{5}{|l|}{ Predicted call type } \\
\hline & Whistle Type 1 & Whistle Type 2 & Whistle Type 3 & Chitter & Purr \\
\hline Whistle Type 1 & $\begin{array}{l}100.0 \\
(18)\end{array}$ & & & & \\
\hline Whistle Type 2 & $\begin{array}{l}10.5 \\
(2)\end{array}$ & $\begin{array}{l}89.5 \\
(17)\end{array}$ & & & \\
\hline Whistle Type 3 & & & $\begin{array}{l}100.0 \\
(6)\end{array}$ & & \\
\hline Chitter & & & & $\begin{array}{l}100.0 \\
(8)\end{array}$ & \\
\hline Purr & & & & & $\begin{array}{l}100.0 \\
(5)\end{array}$ \\
\hline
\end{tabular}




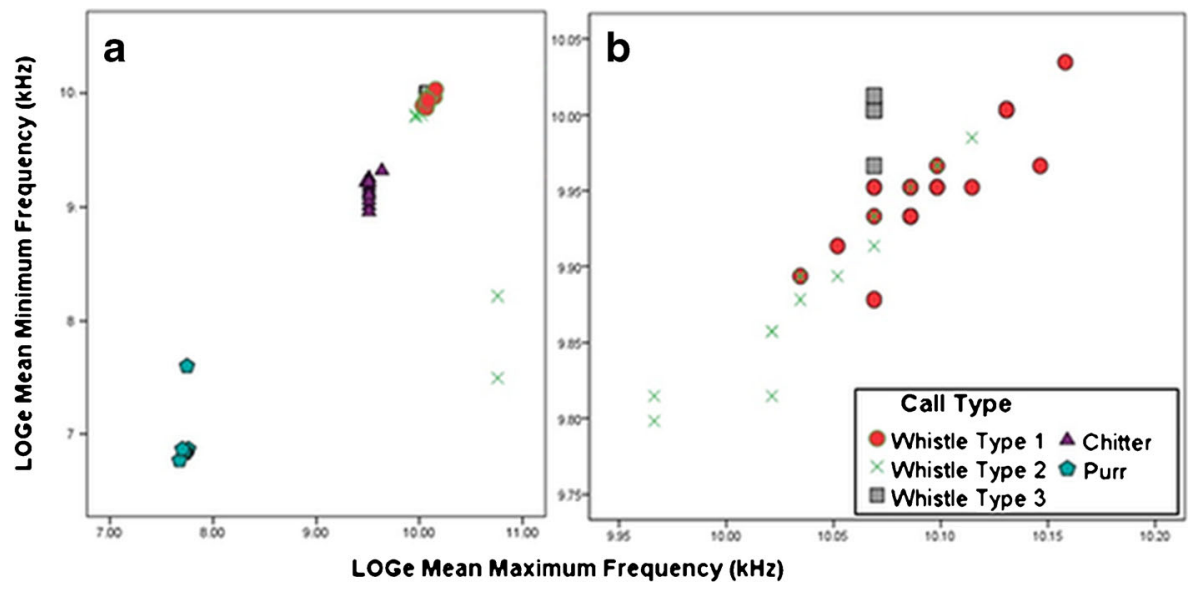

Fig. 4 Scatterplots of the first two principal components in our DFA classification analysis for all five Microcebus sambiranensis call types (a) and a zoomed in version of the three whistle calls (b). All vocalizations were recorded in the Anabohazo forest, northwestern Madagascar (March 27, 2015-May 31, 2015).

The mean acoustic parameters of Whistle Type 1 were all significantly different between M. sambiranensis, M. murinus, and M. rufus (Table V). When Bonferroni

Table V Comparison of the acoustic parameters of Whistle Calls in three mouse lemur species

\begin{tabular}{|c|c|c|c|c|c|c|c|}
\hline \multicolumn{8}{|l|}{ Whistle calls } \\
\hline \multirow[t]{2}{*}{ Species } & \multicolumn{2}{|c|}{ M. sambiranensis } & \multicolumn{2}{|c|}{ M. murinus } & \multicolumn{2}{|c|}{ M. rufus } & \multirow[t]{2}{*}{ ANOVA } \\
\hline & Mean & SD & Mean & SD & Mean & SD & \\
\hline Mean start frequency $(\mathrm{kHz})$ & 20.7 & \pm 0.60 & 14.3 & \pm 1.60 & 18.3 & \pm 3.40 & $\begin{array}{l}\mathrm{df}=2 \\
F=54.544 \\
P<0.001\end{array}$ \\
\hline Mean end frequency $(\mathrm{kHz})$ & 23.4 & \pm 1.00 & 14.3 & \pm 2.00 & 17.4 & \pm 3.90 & $\begin{array}{l}\mathrm{df}=2 \\
F=72.401 \\
P<0.001\end{array}$ \\
\hline Mean minimum frequency $(\mathrm{kHz})$ & 20.7 & \pm 0.75 & 13.8 & \pm 1.70 & 17.2 & \pm 3.80 & $\begin{array}{l}\mathrm{df}=2 \\
F=48.042 \\
P<0.001\end{array}$ \\
\hline Mean maximum frequency $(\mathrm{kHz})$ & 27.1 & \pm 1.24 & 15.6 & \pm 1.50 & 18.7 & \pm 3.40 & $\begin{array}{l}\mathrm{df}=2 \\
F=158.328 \\
P<0.001\end{array}$ \\
\hline Mean duration (s) & 0.158 & \pm 0.02 & 0.128 & \pm 0.05 & 0.084 & \pm 0.06 & $\begin{array}{l}\mathrm{df}=2 \\
F=14.382 \\
P<0.001\end{array}$ \\
\hline Interval (s) & 1.433 & \pm 0.13 & 0.223 & \pm 0.07 & 0.127 & \pm 0.06 & $\begin{array}{l}\mathrm{df}=2, \\
F=1646.568, \\
P<0.001\end{array}$ \\
\hline
\end{tabular}

Vocalizations of Microcebus sambiranensis were recorded in the Anabohzo forest, northwestern Madagascar (March 27, 2015-May 31, 2015). Data for Microcebus murinus and M. rufus are from Zimmermann et al. (2000), where all vocalizations were recorded at the Institute of Zoology, University of Veterinary Medicine Hanover (1990-1998) 
correction was applied to our ANOVA analysis ( $a=0.05 / 6 ; a=0.003)$, the results for all six comparisons were still statistically significant $(P<0.001)$.

\section{Acoustic Survey of Habitat Preference}

We recorded 27 vocalization instances for Microcebus sambiranensis during $720 \mathrm{~h}$ of acoustic survey recording, a rate of 0.05 successful recordings per survey hour. There was a significant difference in mouse lemur call presence between habitat types (general linear model: $F_{3,14}=16.000, P<0.001$ ). We recorded significantly more mouse lemur calls in secondary forest $\left(9, F_{1,3}=5.559, P=0.033\right)$, riparian forest $(6$, $\left.F_{1,3}=6.000, P=0.028\right)$, and forest edge $\left(12, F_{1,3}=56.000, P<0.001\right)$ compared to primary forest $(0)$.

\section{Discussion}

We identified and correctly classified five distinct vocal types for Microcebus sambiranensis that were similar in acoustic structure and function to calls of other mouse lemur species. We named these calls according to the corresponding call types in the vocal repertoires of the closely related M. murinus and M. rufus (Glatston 1979; Zimmermann et al. 2000). Although two of the vocal types, Whistle Type 1 and Whistle Type 2, were clearly related and possessed similar properties, we found a significant statistical difference in their acoustic structure, so we propose them as separate call types. We found species differences in the spectrograms of the call types. For example, the Purr call of M. sambiranensis is at a lower frequency than that of the M. murinus Purr call (Glatston 1979) and both the Whistle Type 1 and Whistle Type 2 calls of $M$. sambiranensis are at higher frequencies than whistle calls of M. murinus. There are also similarities in the whistle calls of different species. M. sambiranensis and M. murinus whistle calls have rising frequencies throughout the call (Glatston 1979; Zimmermann et al. 2000). The Whistle Type 3 call of M. sambiranensis is similar to some of the short whistle calls described for M. murinus and M. rufus by Zimmermann et al. (2000), as it is multiunit with interunit intervals that are less than double the duration of the call's units. Additionally, the Chitter call of M. sambiranensis is very similar in spectrographic appearance to the Chitter call described for M. murinus (Glatston 1979).

We found significant differences among the three species in all the acoustic parameters we tested for whistle calls. Our spectrogram analysis of the other call types described here for Microcebus sambiranensis also differ from spectrograms of the same call types in M. murinus and M. rufus (Glatston 1979; Zimmermann et al. 2000). These results support our hypothesis that the vocal repertoires of the three mouse lemur species have distinctive acoustic parameters. We did not perform statistical comparisons of the acoustic properties of the other call types described here for M. sambiranensis and the same calls in M. murinus and M. rufus because our sample sizes of high-quality recordings were too small for Whistle Type $3(N=6)$ and the Purr $(N=6)$. Also, there are no quantitative acoustic data on the Chitter call of other mouse lemur species, so statistical comparisons between the three mouse lemur taxa for this call type was not possible. 
The findings of our acoustic survey suggest that $M$. sambiranensis prefers secondary growth habitats with younger trees, although we cannot rule out habitat differences in detection. We recorded no mouse lemur vocal activity in the primary forest sites. M. sambiranensis may avoid primary forest because the thick branches of old growth trees expose them to attack from nocturnal predators such as owls and snakes (Perret 1998). Secondary forest has denser growth that offers better protection for the small-bodied mouse lemurs. The canopy in the primary forest was well in excess of $20 \mathrm{~m}$ and vocalizations of mouse lemurs that may have been within the primary forest canopy would not have carried far enough to have been picked up by our acoustic recorder. Thus M. sambiranensis may use primary forest but we were unable to confirm this with our acoustic survey. Also, we did not visually observe any $M$. sambiranensis in primary forest habitat.

Our recording rates of 0.05 recordings per hour suggest that acoustic surveys are not an efficient way to collect large quantities of mouse lemur calls for vocal repertoire compilation or to investigate vocal activity patterns. Radio-tracking and recording calls of collared mouse lemurs produced better results with more than double the vocal recordings in half the recording time. The acoustic survey recording rate was likely affected by the position of the recording equipment. For example, if a mouse lemur vocalized from high in a canopy it is likely that the acoustic recorder would not have recorded the call as it would have been too far away. Additionally, the calls of mouse lemurs are comparatively low amplitude compared to the calls of other forest animals and the acoustic recorder would have to be in close proximity of the individual emitting the call. These factors should be taken into account in future acoustic surveys of cryptic primate vocal activity.

Further research, with some methodological adjustments, is needed to expand our knowledge of this species' vocal repertoire. Our equipment in this study limited our sampling rate to a maximum of $96 \mathrm{kHz}$, meaning that we lost some of the upper harmonics in our recordings. In future studies, we will use equipment capable of a sampling rate double the highest target frequency for mouse lemurs, i.e., a sampling rate of $200 \mathrm{kHz}$ (Braune et al. 2005), which will ensure the upper harmonics are not cut from our recordings.

There have been many studies of the vocalizations of Microcebus murinus both in situ and ex situ. The vocal repertoire of M. murinus contains more call types than those described here for M. sambiranensis (Glatston 1979), suggesting that the repertoire presented here is not comprehensive. Data collection for this study took place outside the suspected mating season of this species (September to December), the period leading up to and including the first part of the wet season (Radespiel 2006); thus, it is likely that calls used in mating and associated social contexts, such as the Trill (Leliveld et al. 2011) are missing from the repertoire we describe. We also observed very few social and agonistic interactions, so we probably missed associated vocalizations, such as the Grunt and Tsak calls observed in M. murinus (Leliveld et al. 2011). Other call types described for other Microcebus species are infant specific or used between a mother and her offspring, such as the Infant Distress Call, Elimination Call, and the Whitter (Glatston 1979). We did not record these classes of calls as we did not observe any infants. Finally, the M. murinus Disturbance Call has been observed only in captivity and we found nothing similar in this study (Glatston 1979).

The understanding of species-specific acoustic communication is important for the field identification of cryptic, nocturnal primate species and has valuable implications 
for conservation (Seiler et al. 2015). The European Association for the Study and Conservation of Lemurs (AEECL) and Mikajy Natiora, two nongovernmental organizations active in Madagascar that endeavour to protect several Endangered lemur species, use the scientific understanding of species habitat use to target specific forest habitat types with their long-term reforestation program. This study will be used to inform these reforestation efforts to restore degraded habitats that are important for the survival of Microcebus sambiranensis. The information provided in this study will also help these nongovernmental organizations to select locations for long-term monitoring of the Sambirano mouse lemur. Additionally, they can use loud call acoustic surveys, such as the one used in this study, to estimate population densities and develop lowcost, long-term remote acoustic sampling tools. These will act as remote acoustic sampling tools to assess the population distribution of the species, as there are currently no conservation methods in place for this Endangered species (Andriaholinirina et al. 2014).

Most Microcebus species are classified as either Endangered or Critically Endangered and most are unstudied (Andriaholinirina et al. 2014). To further the scientific understanding of mouse lemur acoustic communication, we need to compile vocal repertoires of unstudied Microcebus species to explore the phylogenetic and ecological factors that shape them. For example, we can ask whether the vocal repertoires of more closely related species are more similar in their acoustic properties than more genetically distinct species, and to what extent environmental factors influence mouse lemur vocal repertoires. These factors are particularly important to consider because vocal behavior can reveal the genetic fitness and adaptability of a species (Terry et al. 2005).

\section{Conclusion}

We described five distinct call types for Microcebus sambiranensis relating to communication over short and long distances and distress. The acoustic parameters of one call type, Whistle Type 1, differed significantly from those described for other mouse lemur species. An acoustic survey revealed that $M$. sambiranensis may prefer secondary growth habitats with denser vegetation over old-growth primary forest. Despite the acoustic survey's success in suggesting the habitat preference of M. sambiranensis, it was not an efficient method to record large quantities of mouse lemur calls for vocal repertoire compilation, although it is a useful, noninvasive method to explore the distribution and habitat preferences of a mouse lemur species in a study site. The acoustic traits of the Microcebus genus remain poorly understood, despite their potential to reveal the genetic fitness and environmental adaptability of a species. Knowledge of vocal communication can reveal ecological and social traits of species that are important for the development of conservation methods. The Microcebus genus is threatened with extinction. Compiling vocal inventories for more species would allow us to further unravel the question of how phylogeny and environmental influences shape their methods of acoustic communication.

Acknowledgments We thank Rufford Small Grants for Nature Conservation, the Mohammed Bin Zayed Species Conservation Fund, IDEAWild, the European Association for the Study and Conservation of Lemurs (AEECL), and Primate Conservation Incorporated for kindly funding this research. We are indebted to 
Dr. Christoph Schwitzer for his institutional help, Dr. Sylviane Volampeno and Guy Randriatahina of the AEECL and Mikajy Natiora for their logistical assistance and to Madagascar National Parks for their permission to work in Sahamalaza. We also thank Dr. Ed Louis and the Madagascar Biodiversity Partnership for providing veterinary assistance to the project and to all our field guides and research assistants. Finally, we thank four anonymous reviewers for their comments on earlier versions of this manuscript.

\section{Compliance with ethical standards}

Conflict of interest The authors declare that they have no conflict of interest.

\section{References}

Andreone, F., Vences, M., \& Randrianirina, J. E. (2001). Patterns of amphibian and reptile diversity at Berara forest (Sahamalaza peninsula), NW Madagascar. Italian Journal of Zoology, 68, 235-241.

Andriaholinirina, N., Baden, A., Blanco, M., Chikhi, L., Cooke, A., et al. (2014). Microcebus sambiranensis. The IUCN red list of threatened species 2014: E.T41572A16113693.

Baldo, S., \& Mennill, D. J. (2011). Vocal behaviour of great curassows, a vulnerable Neotropical bird. Journal of Field Ornithology, 82, 249-258.

Birkinshaw, C. R. (2004). Priority areas for plant conservation. Ravintsara, 2, 14-15.

Braune, P., Schmidt, S., \& Zimmermann, E. (2005). Spacing and group coordination in a nocturnal primate, the golden brown mouse lemur (Microcebus ravelobensis): The role of olfactory and acoustic signals. Behavioural Ecology and Sociobiology, 58, 587-596.

Braune, P., Schmidt, S., \& Zimmermann, E. (2008). Acoustic divergences in the communication of cryptic species of nocturnal primate (Microcebus spp.) BMC Biology, 6, 1-10.

Cherry, J. A., Izard, M. K., \& Simons, E. L. (1987). Description of ultrasonic vocalisations of the mouse lemur (Microcebus murinus) and the fat-tailed dwarf lemur (Cheirogaleus medius). American Journal of Primatology, 13, 161-185.

Dawson, D. K., \& Efford, M. G. (2009). Bird population density estimated from acoustic signals. Journal of Applied Ecology, 46, 1201-1209.

Gamba, M., Friard, O., \& Giacoma, C. (2012). Vocal tract morphology determines species-specific features in vocal signals of lemurs (Eulemur). International Journal of Primatology., 33, 1453-1466.

Gamba, M., \& Giacoma, C. (2007). Quantitative acoustic analysis of the vocal repertoire of the crowned lemur. Ethology Ecology and Evolution, 19, 323-343.

Ganzhorn, J. U. (1987). A possible role of plantations for primate conservation in Madagascar. American Journal of Primatology, 12, 205-215.

Hackett, T. D., Korine, C., \& Holderied, M. W. (2011). The importance of acacia trees for insectivorous bats and arthropods in the Arava desert. PloS One, 8, 1-11.

Henry, C. S. (1985). Sibling species, call differences and speciation in green lacewings (Neuropoda: Chrysopidae: Crysoperla). Evolution, 39, 965-984.

Hotaling, S., Foley, M. E., Lawrence, N. M., Bocanegra, J., Blanco, M. B., et al (2016). Species discovery and validation in a cryptic radiation of endangered primates: Coalescent-based species delimitation in Madagascar's mouse lemurs. Molecular Ecology. doi:10.1111/mec.13604.

Jolly, G. M., \& Hampton, I. (2011). A stratified random transect design for acoustic surveys of fish stocks. Canadian Journal of Fisheries and Aquatic Sciences, 47, 1282-1291.

Jolly, A., \& Sussman, R. W. (2006). Notes on the history of ecological studies of Malagasy lemurs. In L. Gould \& M. L. Sauther (Eds.), Lemurs: Ecology and adaptation (pp. 19-39). Developments in primatology: Progress and prospects. New York: Springer science+business media.

Kappeler, P. M., \& Rasoloarison, R. M. (2003). Microcebus, mouse lemurs, Tsidy. In S. M. Goodman \& J. P. Benstead (Eds.), The natural history of Madagascar. Chicago: University of Chicago Press.

Leliveld, L. M. C., Scheumann, M., \& Zimmermann, E. (2011). Acoustic correlates of individuality in the vocal repertoire of a nocturnal primate (Microcebus murinus). Journal of the Acoustical Society of America, 129, 2278-2288.

Love, E. K., \& Bee, M. A. (2010). An experimental test of noise-dependent voice amplitude regulation in Cope's grey treefrog, Hyla chrysoscelis. Animal Behaviour, 80, 509-515. 
Marler, P., \& Mitani, J. (1988). Vocal communication in primates and birds: Parallels and contrasts. In D. Todt, P. Goedeking, \& D. Symmes (Eds.), Primate vocal communication (pp. 3-14). Berlin: Springer-Verlag.

Masters, J. C. (1991). Loud calls of Galago crassicaudatus and G. garnettii and their relation to habitat structure. Primates, 32, 153-167.

Masters, J. C., \& Couette, S. (2015). Characterizing cryptic species: A morphometric analysis of craniodental characters in the dwarf galago genus Galagoides. American Journal of Physical Anthropology, 158, 288299.

Mittermeier, R. A., Ganzhorn, J. U., Konstant, W. R., Glander, K., Tattersall, I., et al (2008). Lemur diversity in Madagascar. International Journal of Primatology, 29, 1607-1656.

Mittermeier, R. A., Louis, E. E., Richardson, M., Schwitzer, C., Lingrand, O., et al (2010). Lemurs of Madagascar (3rd ed.). Arlington: Conservation International.

Munds, R. A., Nekaris, K. A. I., \& Ford, S. M. (2013). Taxonomy of the Bornean slow loris, with new species Nycticebus kayan (primates, Lorisidae). American Journal of Primatology, 75, 46-56.

Nietsch, A., \& Kopp, M. L. (1998). Role of vocalization in species differentiation of Sulawesi tarsiers. Folia Primatologica, 69, 371-378.

Obrist, M. K. (1995). Flexible bat echolocation: The influence of individual, habitat and conspecifics on sonar signal design. Behavioural Ecology and Sociobiology, 36, 207-219.

Penny, S. G., Andreone, F., Crottini, A., Holderied, M. W., Rakotozafy, L. S., et al (2014). A new species of the Boophis rappiodes group (Anura, Mantellidae) from the Sahamalaza peninsula, northwest Madagascar, with acoustic monitoring of its nocturnal calling activity. ZooKeys, 435, 111-132.

Perret, M. (1998). Advantage of nest-sharing in a solitary primate, the lesser mouse lemur (Microcebus murinus). Journal of Mammalogy, 79, 1093-1102.

Project ZICOMA (1999). Les zones d'importance pour la conservation des oiseaux a Madagascar. Antananarivo: Project ZICOMA.

Radespiel, U. (2006). Ecological diversity and seasonal adaptations of mouse lemurs (Microcebus spp.). In L. Gould \& M. L. Sauther (Eds.), Lemurs: Ecology and adaptation (pp. 211-233). Developments in primatology: Progress and prospects. New York: Springer science+business media.

Randriatahina, G., Ratsoavina, F., Volampeno, S., \& Schwitzer, C. (2014). Rapid assessment of lemur species in Anabohazo forest, Sahamalaza-Iles Radama National Park. Lemur News, 18, 22-24.

Rasoloarison, R. M., Goodman, S. M., \& Ganzhorn, J. U. (2000). Taxonomic revision of mouse lemurs (Microcebus) in the western portions of Madagascar. International Journal of Primatology, 21, 963-1023.

Rasoloharijaona, S., Randrianambinina, B., Braune, P., \& Zimmermann, E. (2006). Loud calling, spacing and cohesiveness in a nocturnal primate, the Milne-Edwards sportive lemur (Lepilemur edwardsi). American Journal of Physical Anthropology, 129, 591-600.

Rode-Margono, E. J., Schwitzer, C., \& Nekaris, K. A. I. (2016). Morphology, behaviour, ranging patterns and habitat use of the northern giant mouse lemur Mirza zaza in Sahamalaza, northwestern Madagascar. In S. Lehman, U. Radespiel, \& E. Zimmermann (Eds.), The dwarf and mouse lemurs of Madagascar: Biology, behaviour and conservation biogeography of the Cheirogaleidae (pp. 235-254). Cambridge: Cambridge University Press.

Scheumann, M., Zimmermann, E., \& Deichsel, G. (2007). Context-specific calls signal infants' needs in a strepsirrhine primate, the gray mouse lemur (Microcebus murinus). Developmental Psychobiology, 49, 708-718.

Schwitzer, C., Glatt, L., Nekaris, K. A. I., \& Ganzhorn, J. U. (2011). Responses of animals to habitat alteration: An overview focussing on primates. Endangered Species Research, 14, 31-38.

Schwitzer, C., Mittermeier, R. A., Davies, N., Johnson, S., Ratsimbazafy, J., et al (2013). Lemurs of Madagascar: A strategy for their conservation 2013-2016. Bristol, UK: IUCN, SSC Primate Specialist Group, Bristol Conservation and Science Foundation, and Conservation International.

Schwitzer, N., Kaumanns, W., Seitz, P. C., \& Schwitzer, C. (2007b). Cathemeral activity patterns of the blueeyed black lemur Eulemur macaco flavifrons in intact and degraded forest fragments. Endangered Species Research, 3, 239-247.

Schwitzer, N., Randriatahina, G. H., Kaumanns, W., Hoffmeister, D., \& Schwitzer, C. (2007a). Habitat utilization of blue-eyed black lemurs, Eulemur macaco flavifrons (gray, 1867), in primary and altered forest fragments. Primate Conservation, 22, 79-87.

Seiler, M., Randriatahina, G. H., \& Schwitzer, C. (2010). Ongoing threats to lemurs and their habitat inside the Sahamalaza-Iles Radama National Park. Lemur News, 15, 7-9.

Seiler, M., Schwitzer, C., Gamba, M., \& Holderied, M. (2013). Interspecific semantic alarm call recognition in the solitary Sahamalaza sportive lemur, Lepilemur sahamalazensis. PloS One, 8, 1-12.

Seiler, M., Schwitzer, C., \& Holderied, M. W. (2015). Call repertoire of the Sahamalaza sportive lemur, Lepilemur sahamalazensis. International Journal of Primatology, 36, 647-665. 
Slabbekoorn, H., \& Smith, T. B. (2002). Habitat-dependent song divergence in the little greenbul: An analysis of environmental selection pressures on acoustic signals. Evolution, 56, 1849-1858.

Terry, A. M. R., Peake, T. M., \& McGregor, P. K. (2005). The role of vocal individuality in conservation. Frontiers in Zoology. doi:10.1186/1742-9994-2-10.

Volampeno, M. S. N., Randriatahina, G. H., Kalle, R., Wilson, A. L., \& Downs, C. T. (2015). A preliminary population viability analysis of the critically endangered blue-eyed black lemur (Eulemur flavifrons). African Journal of Ecology, 53, 419-427.

Whitehead, J. M. (1995). Vox Allouattinae: A preliminary survey of the acoustic characteristics of longdistance calls of howler monkeys. International Journal of Primatology, 16, 121-144.

Wiley, R. H., \& Richards, D. G. (1982). Adaptations for acoustic communication in birds: Sound transmission and signal detection. In D. E. Kroodsma \& E. H. Miller (Eds.), Acoustic communication in birds (Vol. 1, pp. 131-181). New York: Academic Press.

Wilme, L., Goodman, S. M., \& Ganzhorn, J. U. (2006). Biogeographic evolution of Madagascar's microendemic biota. Science, 312, 1063-1065.

Zimmermann, E., Vorobieva, E., Wrogemann, D., \& Hafen, T. (2000). Use of vocal fingerprinting for specific discrimination of gray (Microcebus murinus) and rufous mouse lemurs (Microcebus rufus). International Journal of Primatology, 21, 837-852. 